\title{
Health professional's job satisfaction and its determinants in Ethiopia: a systematic review and meta-analysis
}

\author{
${\text { Bekahegn Girma }{ }^{1 *} \mathbb{D} \text {, Jemberu Nigussie }{ }^{1}, \text { Alemayehu Molla }^{2} \text { and Moges Mareg }}^{3}$
}

\begin{abstract}
Background: Health professional's job satisfaction is directly related to patient satisfaction and quality of care. Without satisfied health professionals the health system is not functional, and the national and global health related plans are not achieved. However, little is known on the level of health professional's job satisfaction in sub Saharan African countries including Ethiopia. In addition, in Ethiopia there is no summarized evidence helped us an input to design strategies. Therefore, we aimed to assess the pooled prevalence of health professional's job satisfaction and its determinants in Ethiopia.
\end{abstract}

Methods: Articles were searched from PubMed, PsycINFO, Hinari, Science Direct, web of science and African journal of online (AJOL) databases, Google and Google scholar. A standardized Microsoft excel spread sheet and STATA software version 16 were used for data extraction and analysis respectively. We followed the Preferred Reporting Items for Systematic reviews and Meta-Analysis to write this report. A random effect meta-analysis model was used to determine the pooled prevalence of job satisfaction. $I^{2}$ was done to check heterogeneity. Egger's test and funnel plot were conducted to detect publication bias. Subgroup analysis was also conducted. Association was expressed through pooled odd ratio with a $95 \% \mathrm{Cl}$.

Result: In this review and meta-analysis, a total of 29 studies were included. The pooled prevalence of health professional's job satisfaction was 46.17\% [95\% Cl $(43.08,49.26)]$. The heterogeneity and publication bias test results were $\mathrm{I}^{2}=87.3 \%, P<0.001$ and Eggers', $P=0.16$. Female sex; OR: $2.20[95 \% \mathrm{Cl}(1.63,2.97)]$, working environment; OR: $9.50[95 \% \mathrm{Cl}(6.25,14.44)]$, opportunity for professional growth and development; OR: 5.53 [95\% Cl $(1.56,19.56)]$, staff relationship; OR: 3.89 [95\% Cl $(1.65,9.17)]$ and supportive supervision; OR: 5.32 [95\% Cl $(1.77,15.92)]$ were associated with health professional's job satisfaction.

Conclusion: More than half of professionals were dissatisfied with their jobs. Therefore, the ministry of health and stakeholders better to design strategies to increase the level of satisfaction. Furthermore, it is better to strengthen staff relationship and making the working environment more attractive and equipped.

Keywords: Health professionals, Job satisfaction, Determinants, Ethiopia, Meta-analysis

\footnotetext{
* Correspondence: Bekahegng@du.edu.et

'Department of Nursing, College of Medicine and Health Science, Dilla University, Dilla, Ethiopia

Full list of author information is available at the end of the article
}

(c) The Author(s). 2021 Open Access This article is licensed under a Creative Commons Attribution 4.0 International License, which permits use, sharing, adaptation, distribution and reproduction in any medium or format, as long as you give appropriate credit to the original author(s) and the source, provide a link to the Creative Commons licence, and indicate if changes were made. The images or other third party material in this article are included in the article's Creative Commons licence, unless indicated otherwise in a credit line to the material. If material is not included in the article's Creative Commons licence and your intended use is not permitted by statutory regulation or exceeds the permitted use, you will need to obtain permission directly from the copyright holder. To view a copy of this licence, visit http://creativecommons.org/licenses/by/4.0/ The Creative Commons Public Domain Dedication waiver (http://creativecommons.org/publicdomain/zero/1.0/) applies to the data made available in this article, unless otherwise stated in a credit line to the data. 


\section{Background}

Job satisfaction is a positive, favourable attitude and feeling what people have about their job $[1,2]$. Health professional's job satisfaction is significantly related with quality of care and patient satisfaction [3]. To achieve the Sustainable Development Goals (SDGs) strategy was planned on human resources by World Health Organization (WHO) [4]. Furthermore, motivation of the health care providers has a pivotal role for achievement of this strategy and it depends on many factors. Job satisfaction is one of the most important factors [5].

A high level of job satisfaction has a positive effect on workers' health related quality of life [6, 7], job performance [8-10], retention in work [11], quality of healthcare delivery $[12,13]$ and patient satisfaction $[14,15]$. However, low satisfaction may result in staff turnover, tiredness, absenteeism, intention to leave, burnout, undesirable job performance and poor quality of service to clients [16-19].

Shortage of skilled health professionals is a global burden and it is high in most African countries including Ethiopia [20]. According to WHO report by the year 2035 the health workforce shortage will reach up to 12.9 million; 47 and 25\% of the shortfall will be in South-East Asia and Africa [21]. To prevent this challenge the health profession's intention to stay should be increased by increasing their job satisfaction level [22]. Therefore, determining the level of job satisfaction has paramount significance. Studies conducted in Africa on job satisfaction showed a prevalence that ranges from 17.4 [23] to $82.6 \%$ [24].

Previous studies identified some determinants for health professional's job satisfaction such as sex, age, educational status, year of experience, working environment, workload, salary, recognition and opportunity for professionals growth and development [25-32].

In Ethiopia, there is no representative and summarized data on health professional's job satisfaction. The conducted single studies showed inconsistent prevalence that ranges from 31.7 [33] to $74.4 \%$ [34]. Besides, there are some contradicting findings on factors associated with job satisfaction. Therefore, this systematic review and meta-analysis was aimed to estimate the pooled prevalence of health professional's job satisfaction and its determinants in Ethiopia.

\section{Methods}

\section{Searching strategy}

We followed the Preferred Reporting Items for Systematic reviews and Meta-Analysis (PRISMA) guidelines to write this review and meta-analysis [35]. The presence of similar reviews was checked using this link https:// www2.le.ac.uk/library/find/databases/p/Prospero. Primary articles were searched from PubMed, PsycINFO,
Hinari, Science direct, web of science and African journal of online (AJOL) databases. Moreover, grey literatures were retrieved from Google and Google scholar. The reference list of published articles was searched to recognize other relevant articles that didn't showed in databases. Searching was restricted to studies conducted from 2010 until 2020 on humans and full English version articles. Probing of primary articles was started on September 20, 2020 and ended on October 5, 2020. We used "prevalence OR magnitude AND health care professionals OR health care providers OR health workers AND Ethiopia" for objective one and "Determinants OR factors OR predictors AND health care professionals OR health care providers OR health workers AND Ethiopia for the second objective as keywords for searching. Published and unpublished articles were searched and included in this systematic review and meta-analysis. Endnote version X6 was used to manage citations and to check duplication of articles.

\section{Eligibility criteria}

BG and JN independently executed eligibility assessment in an unblinded identical manner based on the stated inclusion and exclusion criteria. We solved disagreements by consensus and invitation of the remaining two authors.

\section{Inclusion criteria}

Observational studies conducted between 2010 and 2020 in Ethiopia among health professionals and published in English language were included. Furthermore, articles reporting the level of health professional's job satisfaction in proportion were included. Published and unpublished full articles reported the prevalence and/ or associated factor were considered.

\section{Exclusion criteria}

Studies qualitative in design were excluded.

\section{Outcome measures}

In this systematic review and meta-analysis two objectives were assessed. The first was to estimate the pooled prevalence of job satisfaction among health professionals in Ethiopia and it was estimated by dividing the number of satisfied health care professionals to the total number of health care professionals included in this review and meta-analysis, and multiplied by 100 . The second objective was to determine the pooled effects of factors on health professional's job satisfaction in Ethiopia. In this systematic review and meta-analysis, variables identified as a factor for job satisfaction in at least three studies were considered. We used odds ratio (OR) to express the pooled effect. 


\section{Quality assessment and data extraction}

Newcastle Ottawa Scale was used to assess the quality of studies [36]. BG and JN have appraised the studies independently using the above tool. The following items were included to evaluate the methodological quality, comparability, and the ascertainment of the outcome. The tool encompassed 10 criteria's for rating different quality elements and studies scored 6 and above out of 10 were included in to this review and meta-analysis. During the quality assessment any disagreements were solved through discussion and before agreement reached weighted kappa index was done, which was 0.76 [37].

BG and JN extracted all the necessary data independently using a standardized Microsoft Excel. Two data extraction formats, one for each objective were used. The first data extraction format that was prepared for objective one (prevalence of job satisfaction) comprised author name, publication year, region the study conducted, study design, sample size, response rate, profession and prevalence of job satisfaction. To extract data for objective two (factors for job satisfaction) we used two by two tables. Any disagreements during the data extraction time between the two authors (BG and $J N$ ) were resolved through discussion, two fold checking the varying data together, and through invitation of either of the remaining two authors.

\section{Publication bias and heterogeneity}

To check publication bias funnel plots [38] and Egger's statistical test [39] were conducted. We used a $p$-value < 0.05 to declare the statistical significance of publication bias. After a comprehensive examination of the included studies, $\mathrm{I}^{2}$ test was conducted to assess the heterogeneity and declared as low, moderate, and high heterogeneity if it is $<50,50-75 \%$, and $>75 \%$ respectively [40].

\section{Statistical method and analysis}

All extracted data from each study using a Microsoft excel spread sheet were exported to STATA version 16 software for analysis. Binomial distribution formula was used to calculate the standard error of prevalence for each original article. Due to high heterogeneity between the included studies we used a random-effect model for analysis [41]. Subgroup analysis based on profession type and region was conducted to check the source of heterogeneity [42-44]. Using separate groups of meta-analysis the effect of the selected associated factors on the outcome variable was examined. We used texts, tables, forest plots, and OR with 95\% confidence intervals (CI) to describe the features of the included articles and to display the finding of this review and meta-analysis.

\section{Results}

Study search and selection

By fixing the searching scope on full-text articles, human studies, published in English language between 2010 \& 2020, we found a total of 2280 primary articles from PubMed HINARI, web of science, PsycInfo, AJOL and science direct databases. Furthermore, we also found from Google scholar and Google. Of which, a total of 1039 and 1204 articles were excluded due to duplication and unrelated to our study that was screened by title and abstract respectively. In this systematic review and meta-analysis, only 37 articles were selected for full reading and 8 were excluded; 4 due to the overall job satisfaction level was not reported [45-48], 1 due to poor quality, since very small sample size used [34], 2 articles due to the outcome variable was not reported with proportion $[49,50]$ and 1 due to it was qualitative study [51]. Lastly, a total of 29 articles that fulfill all the inclusion criteria's were selected for meta-analysis [16, 33, 52-78] (Fig. 1).

\section{Characteristics of the included studies}

All of the included articles were cross-sectional studies. The study was conducted among 8368 health care professionals working in Ethiopia. The least sample size was on study done at Mekelle (60) [62] and the highest was in Amhara region (657) [33]. Only three articles were conducted before 2015 [16, 54, 55]. The majority, $9(30 \%)$ of studies were conducted in Oromia region $[16,52,54,62,68,69,72,75,76]$ and only one study was conducted in SNNP region [55]. Simple random sampling technique was used by sixteen $(53.3 \%)$ studies to select study participants [33, $52,55,56,59-61,65-69,71-73,76]$. In this review, the response rate of the included articles was ranged from 84.8 [57] to $100 \%$ [69]. The highest prevalence of job satisfaction was reported on study done in Mekelle city (67.3\%) [62] and the least was in Amhara region (31.7\%) [33]. Regarding to profession, 14 (46.7\%) were conducted by including all health professionals $[16,33,63,65,66,68-70,72,74-78]$ and 4 on anaesthesia and midwiferies; 2 for each [61, 64, 68, 71] (Table 1).

\section{Meta-analysis}

As shown on Fig. 2, forest plot was conducted to show the result of the included studies. Twenty nine studies were included in this systematic review and metaanalysis to estimate the pooled prevalence of health care professional's job satisfaction. The heterogeneity of the included studies was $\mathrm{I}^{2}=87.3 \%$ with $p<0.01$. Due to this heterogeneity, we used the random-effect model to estimate the pooled prevalence of health professional's 


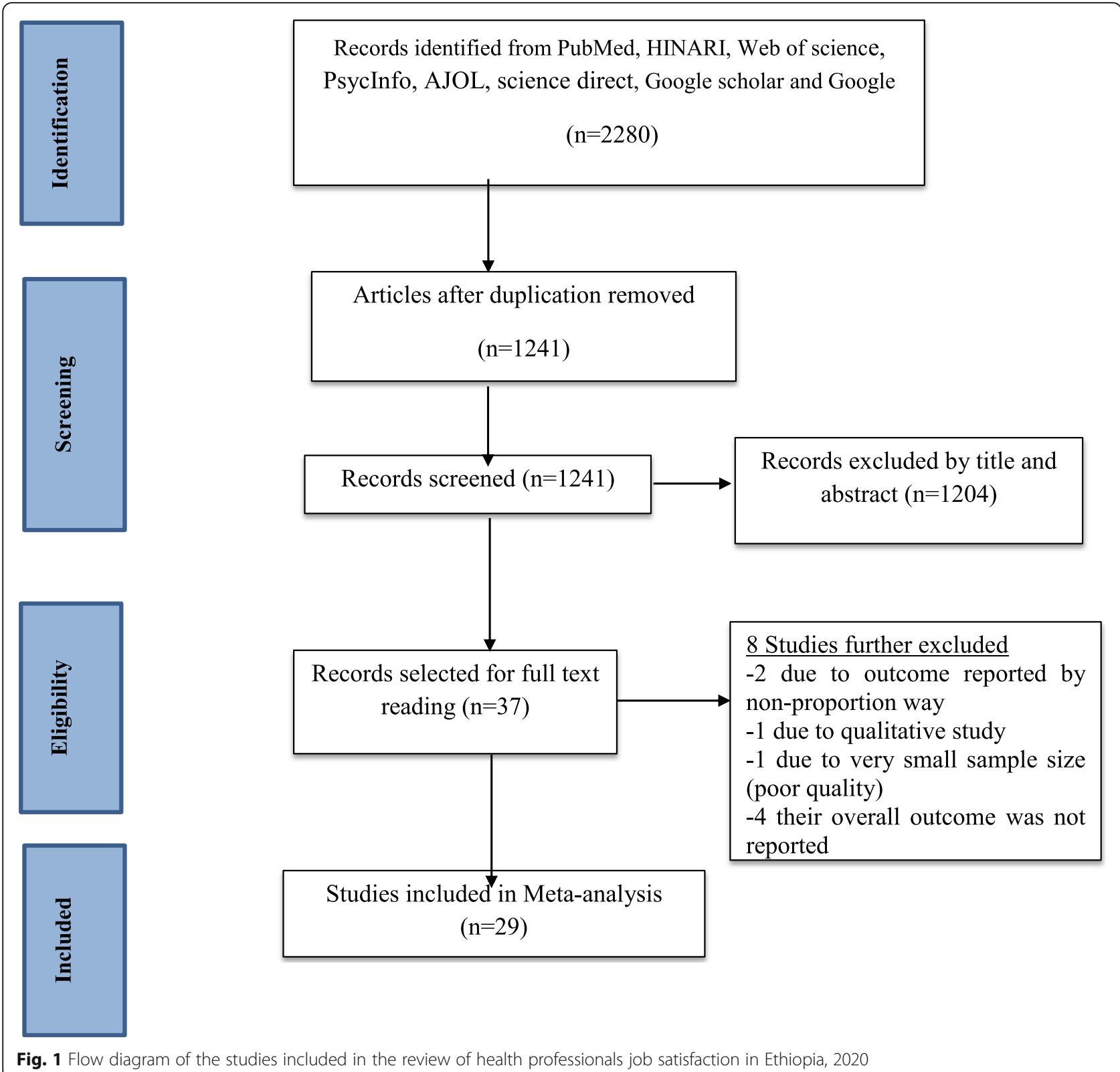

job satisfaction and it was 46.17\%; [95\% CI (43.08, 49.26)]. Based on the subjective inspection of funnel plot, more than half of the studies were distributed within the plot (Fig. 3$)$. In addition, Eggers test $(P=0.16)$ was also done, so we have no evidence for publication bias.

To detect the source of heterogeneity subgroup analysis was conducted based on profession and publication year. As shown in Table 2, the highest pooled prevalence of job satisfaction and heterogeneity were shown among pharmacy professionals $53.18(30.14,76.22) \quad\left(\mathrm{I}^{2}=94.7\right.$, $P<0.01)$. However, there was no significant pooled prevalence difference among studies conducted before 2017, and 2017 and after; $46.24(40.55,51.93)$ and 46.14 $(42.39,49.90)$ respectively.

\section{Factors associated with health professional's job} satisfaction

In the present review and meta-analysis, factors identified as significant for health professional's job satisfaction in at least three primary articles were included. As a result, salary $[53,60,65,75]$, working experience $[33,55$, 67-69, 76] and profession type [33, 66, 69] were identified as factors for job satisfaction in three and above studies, due to they were reported through various category methods that create a difficulty to extract data we exclude them from analysis after discussion and agreement by authors. Support from supervisor $[65,73,76]$, working environment $[56,60,66,72,73,76]$, opportunity for professional growth $[60,74,76]$, sex $[61,69,73]$, 
Table 1 Characteristics of the included articles for health professional's job satisfaction in Ethiopia; $2020(n=29)$

\begin{tabular}{|c|c|c|c|c|c|c|}
\hline Author's & Region & Design & Sample size & Response rate & Prevalence & Profession \\
\hline Temesgn $\mathrm{K}$ et al & Amhara & CS & 657 & 87.5 & 31.7 & Health professionals \\
\hline Deriba BK et al & All & CS & 322 & 95.56 & 41.46 & Health professionals \\
\hline Teka AA et al & Oromia & CS & 305 & 100 & 34.4 & Health professionals \\
\hline Workineh I et al & Oromia & CS & 429 & 98.3 & 46 & Health professionals \\
\hline Geleto A et al & Harare & CS & 420 & 96.43 & 44.2 & Health professionals \\
\hline Ayalew F et al & All & CS & 500 & 84.8 & 60.8 & Nurse \\
\hline Belay YB & Tigray & CS & 60 & 91.6 & 67.3 & Pharmacist \\
\hline Ayele $\mathrm{Y}$ et al & All & CS & 232 & 94.8 & 32.7 & Pharmacist \\
\hline Belay $A$ et al & Oromia & CS & 98 & 100 & 48 & Nurse \\
\hline Wondwossen $Y$ et al & AA & CS & 314 & 95.5 & 37 & Health professionals \\
\hline Kibwana S et al & All & CS & 252 & 100 & 42.5 & Anaesthetics \\
\hline Asegid A et al & SNNP & CS & 278 & 87 & 52.5 & Nurse \\
\hline Meselu BT et al & Tigray & CS & 140 & 100 & 43.57 & Midwifery \\
\hline Salgedo WB et al & Oromia & CS & 260 & 100 & 49.6 & Health professionals \\
\hline Desalegn N et al & Ethiopia & CS & 265 & 91.3 & 45.8 & Anaesthetics \\
\hline Kitaba M et al & All & CS & 417 & 94.7 & 51.8 & Nurse \\
\hline Yami A et al & Oromia & CS & 160 & 90.6 & 41.4 & Health professionals \\
\hline Mengistu MM et al & Oromia & CS & 166 & 100 & 34.9 & Health professionals \\
\hline Fentie DY et al & Amhara & CS & 104 & 94.3 & 46.9 & Health professionals \\
\hline Ahmed SM et al & Oromia & CS & 102 & 95 & 60.8 & Pharmacist \\
\hline Abadiga $M$ et al & Oromia & CS & 266 & 94.7 & 51.3 & Nurse \\
\hline Haile D et al & Amhara & CS & 181 & 98.3 & 54.2 & Nurse \\
\hline Gedif G et al & Amhara & CS & 416 & 92.1 & 54 & Health professionals \\
\hline Bekru ET et al & AA & CS & 234 & 94.4 & 52.9 & Midwifery \\
\hline Azagew AW et al & Amhara & CS & 416 & 97.6 & 49.8 & Nurse \\
\hline Ayalew E et al. & Amhara & CS & 226 & 98.3 & 43.6 & Nurse \\
\hline Mohammed E et al & Oromia & CS & 422 & 92.2 & 47.6 & Health professionals \\
\hline Tadesse $T$ et al & AA & CS & 304 & 96.4 & 43.2 & Health professionals \\
\hline Merga $\mathrm{H}$ et al & All & CS & 422 & 98.3 & 38.5 & Health professionals \\
\hline
\end{tabular}

Hint: All: studies conducted county wide; AA Addis Ababa; CS Cross sectional; Eastern Ethiopia: include Harare and Dire Dawa; SNNP South Nation Nationalities and people

marital status $[58,61,65]$, educational status $[33,61,69$, $76]$, staff relationship [72, 74, 76] and age [59, 69, 76] were factors that fulfill the criteria and selected for meta-analysis. However, support from supervisor, working environment, staff relationship, sex and opportunity for professional growth were identified as significant determinants for health professional's job satisfaction.

In the current review and meta-analysis, health professionals who had good support from their supervisors were 5.3 times more likely to satisfy as compared to their contrary health care professionals (OR: 5.32 [95\% CI $(1.77,15.92)])$. Health professionals who were worked in an attractive or good environment had 9.5 times higher opportunity to satisfy in contrast to their counterparts (OR: 9.50 [95\% CI $(6.25,14.44)])$. Moreover, health professionals who were worked in an organization that provide opportunity for professional growth and development like training and education access had 5.5 times higher satisfaction level than those working in an organization that doesn't provide any opportunity for professional growth and development (OR: 5.53 [95\% CI $(1.56,19.56)])$ (Table 3).

As shown below in Table 3, staff relationship and sex were another factor identified for health professional's job satisfaction. Health professionals who were worked in an organization that had good relationship between staffs and female in sex had 3.8 (OR: 3.89; [95\% CI (1.65, 9.17)]) and 2.2 times (OR: 2.20 [95\% CI $(1.63,2.97)]$ ) more chance to satisfy as compared to their opposite groups respectively. 


$$
\text { Study }
$$$$
\text { ID }
$$

Temesgn $\mathrm{K}$ et al (2018)

Deriba BK et al (2017)

Teka AA et al (2016)

Workineh I et al (2020)

Geleto A et al (2015)

Ayalew $\mathrm{F}$ et al (2019)

Belay YB (2016)

Ayele $Y$ et al (2020)

Belay A et al (2018)

Wondwossen $Y$ et al (2017)

Kibwana S et al (2018)

Asegid A et al (2014)

Meselu BT et al (2020)

Salgedo WB et al (2020)

Desalegn N et al (2015)

Kitaba M et al (2017)

Yami A et al (2011)

Mengistu MM et al (2015)

Fentie DY et al (2018)

Ahmed SM et al (2013)

Abadiga M et al (2019)

Haile D et al (2017)

Gedif $\mathrm{G}$ et al (2018)

Bekru ET et al (2017)

Azagew AW et al (2020)

Ayalew $\mathrm{E}$ et al (2019)

Mohammed E et al (2020)

Tadesse T et al (2015)

Merga $\mathrm{H}$ et al (2019)

Overall ( $($-squared $=87.3 \%, p=0.000$ )

NOTE: Weights are from random effects analysis
ES $(95 \% \mathrm{Cl})$

$31.70(27.90,35.50)$

$41.46(35.96,46.96)$

$34.40(29.07,39.73)$

$46.00(41.24,50.76)$

$44.20(39.36,49.04)$

$60.80(56.15,65.45)$

$67.30(54.90,79.70)$

$32.70(26.50,38.90)$

$48.00(38.11,57.89)$

$37.00(31.54,42.46)$

$42.50(36.40,48.60)$

$52.50(46.21,58.79)$

$43.57(35.36,51.78)$

$49.60(43.52,55.68)$

$45.80(39.52,52.08)$

$51.80(46.87,56.73)$

$41.40(33.38,49.42)$

$34.90(27.65,42.15)$

$46.90(37.02,56.78)$

$60.80(51.08,70.52)$

$51.30(45.13,57.47)$

$54.20(46.88,61.52)$

$54.00(49.01,58.99)$

$52.90(46.32,59.48)$

$49.80(44.94,54.66)$

$43.60(37.05,50.15)$

$47.60(42.64,52.56)$

$43.20(37.56,48.84)$

$38.50(33.82,43.18)$

$46.17(43.08,49.26)$

Fig. 2 Forest plot of the included studies to determine the pooled prevalence of health professional's job satisfaction in Ethiopia, 2020 ( $n=29)$

\section{Discussion}

Job dissatisfaction worsen patient-health professionals ratio and staff turnover [22]. Job satisfaction is strongly associated with workers depression and anxiety [6]. The aim of this review and meta-analysis was to assess the pooled prevalence of health professional's job satisfaction and its determinants in Ethiopia. The pooled prevalence of health professional's job satisfaction was $46.17 \%$ [95\% CI $(43.08,49.26)]$. We used random effect model for pooled analysis of included studies, since heterogeneity was $87.3 \%$ and the Egger test value was 0.06 before excluding one single study done in Harare region with very small sample size (43) [34] and after excluding this single study the value of Egger test was 0.16. While inspecting funnel plot more than half of the articles were within the plot.

Support from supervisor, working environment, staff relationship, sex and opportunity for professional growth were identified as significant determinants for health professional's job satisfaction.

In this review and meta-analysis, the overall pooled prevalence of job satisfaction was lower as compared to studies conducted in South Africa (52.1\%), Malawi
(71\%), Tanzania (82.6\%) [24], Canada 56\% [79], Nepal (76\%) [26], Spain (77.2\%) [80], India (59.6\%) [81], Egypt (61.24\%) [82], China (74.6\%) [3] and the global population job satisfaction level (88\%) [83]. This might be due to variation in socio-economic, health facility quality and payment for health professionals. However, it was high as compared to studies done in Pakistan (41\%) [84], Nigeria (32.9\%) [85] and Uganda (17.4\%) [23]. The discrepancy might be because of study population variation that the last two were conducted on only nurses and the second reason might be due to small sample size in the above studies.

Health professionals who had good support from their supervisors were more likely satisfied. This finding was supported by study done in Pakistan [84] and studies conducted in three African countries [86, 87]. This might be due to the fact that good support from supervisors increases professional's motivation that leads to satisfaction. In addition it might be due to the fact that supportive supervision increase staff job satisfaction level [88].

Working environment of the employees was significantly associated with job satisfaction. Health 


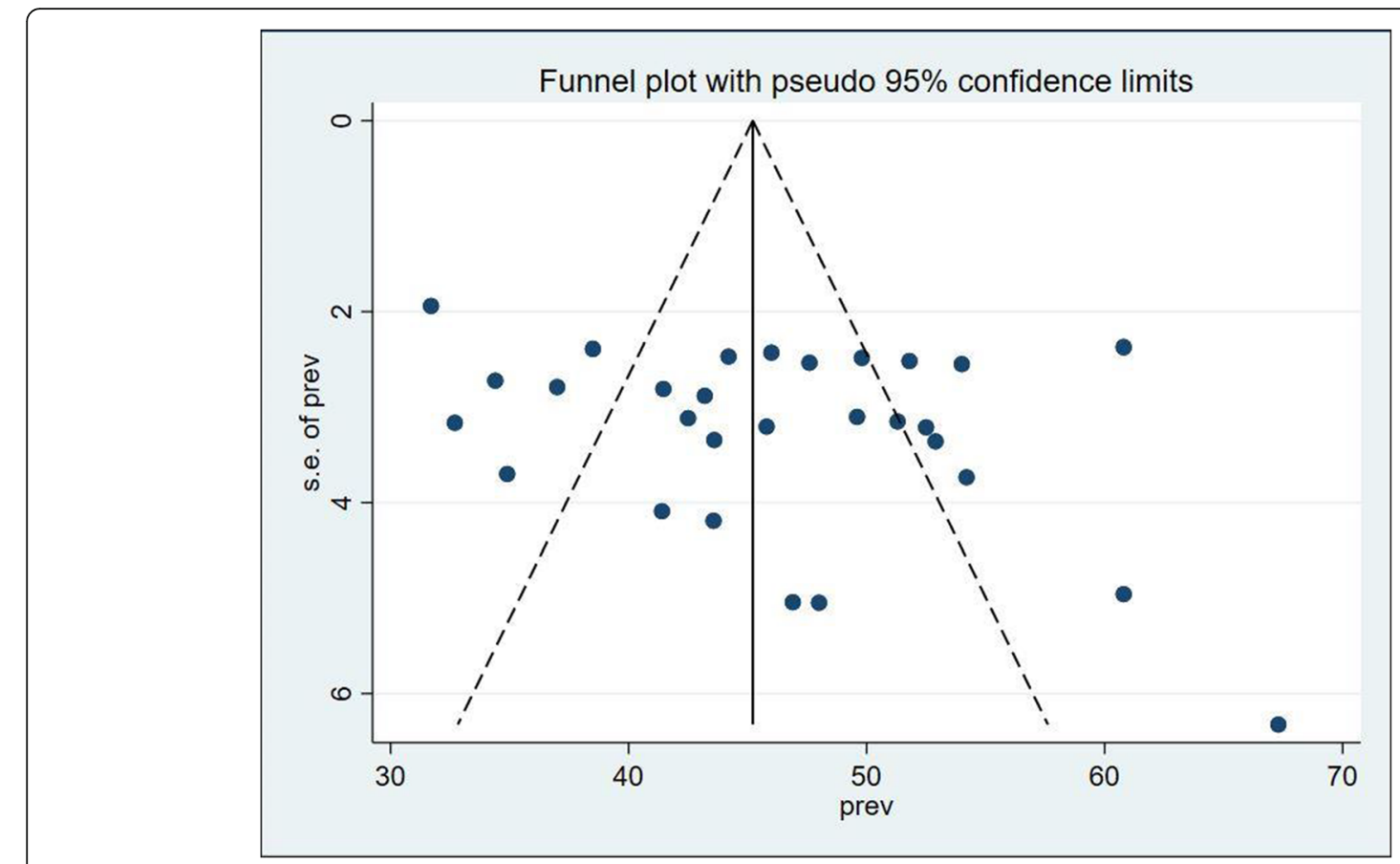

Fig. 3 Funnel plot showing distribution of studies on health professional's job satisfaction in Ethiopia, $2020(n=29)$

professionals who were working in an attractive and good area had 9.5 times more likely satisfied as compared to their counterparts. This finding was supported by qualitative study conducted in Pakistan [89]. This might be the fact that good and attractive working environment have positive psychological and physical influence on employees and motivate them.

In the current review and meta-analysis, health professionals who were working in an organization that had good staff relationship were more satisfied. This finding was supported by studies done in India [90] and Bangladesh [91]. This similarity might be due to good staff relationship create good communication between staffs that leads to good working condition and satisfaction.
Employees who were working in an organization which provide an opportunity for professional growth and development had 5.5 times more odds of satisfaction. This finding was supported by studies conducted in South Africa [92] and Nepal [26]. This might be due to the fact that such kind of opportunity increase professional's income, level of knowledge and motivation that lead to satisfaction with their job. Moreover, it might be due to the fact that professional development have a direct positive effect on job satisfaction [93].

The last determinant identified in this review and meta-analysis was sex. Female health professionals had more satisfied as compared to their counterparts. This finding was supported by studies done in China [3] and USA [94]. This might be because of the fact that female

Table 2 Sub group pooled prevalence of health professional's job satisfaction in Ethiopia; $2020(n=29)$

\begin{tabular}{|c|c|c|c|c|c|}
\hline \multirow[t]{2}{*}{ Variables } & \multirow[t]{2}{*}{ Characteristics } & \multirow{2}{*}{$\begin{array}{l}\text { No. of } \\
\text { studies }\end{array}$} & \multirow[t]{2}{*}{ Prevalence } & \multicolumn{2}{|c|}{ Heterogeneity } \\
\hline & & & & $\mathrm{I}^{2}(\%)$ & $P$ value \\
\hline \multirow[t]{2}{*}{ Publication year } & 2017 and after & 20 & $46.14(42.39,49.9)$ & 88.6 & $<0.01$ \\
\hline & Before 2017 & 9 & $46.24(40.55,51.93)$ & 84.4 & $<0.01$ \\
\hline \multirow[t]{5}{*}{ Profession } & Health professionals & 14 & $42.12(38.45,45.80)$ & 84.2 & $<0.01$ \\
\hline & Nurse & 8 & $51.83(48.07,55.58)$ & 67.8 & $<0.01$ \\
\hline & Pharmacist & 3 & $53.18(30.14,76.22)$ & 94.7 & $<0.01$ \\
\hline & Anaesthetics & 2 & $44.10(39.73,48.48)$ & 0 & 0.46 \\
\hline & Midwifery & 2 & $48.57(39.45,57.69)$ & 66.9 & 0.08 \\
\hline \multicolumn{2}{|c|}{ Overall pooled prevalence } & 29 & $46.17(43.08,49.26)$ & 87.3 & $<0.01$ \\
\hline
\end{tabular}


Table 3 Meta-analysis of factors associated with health professional's job satisfaction in Ethiopia, 2020

\begin{tabular}{|c|c|c|c|c|}
\hline \multirow[t]{2}{*}{ Factors } & \multirow{2}{*}{$\begin{array}{l}\text { Number } \\
\text { of } \\
\text { studies }\end{array}$} & \multirow[t]{2}{*}{ OR $(95 \% \mathrm{Cl})$} & \multicolumn{2}{|c|}{ Heterogeneity } \\
\hline & & & $I^{2}(\%)$ & $P$ value \\
\hline Support from supervisor & 3 & $5.32(1.77,15.92)^{\mathbf{a}}$ & 94.3 & $<0.01$ \\
\hline Condition of working environment & 6 & $9.50(6.25,14.44)^{\mathbf{a}}$ & 76.0 & $<0.01$ \\
\hline Opportunity for professional growth & 3 & $5.53\left(1.56,19.56^{\mathbf{a}}\right.$ & 95.2 & $<0.01$ \\
\hline Sex & 3 & $2.20(1.63,2.97)^{\mathbf{a}}$ & 0 & 0.42 \\
\hline Marital status & 3 & $1.07(0.66,1.75)$ & 68.5 & 0.04 \\
\hline Educational status & 4 & $1.70(0.58,5.00)$ & 93.7 & $<0.01$ \\
\hline Staff relationship & 3 & $3.89(1.65,9.17)^{\mathbf{a}}$ & 88.1 & $<0.01$ \\
\hline Age & 3 & $0.73(0.37,1.44)$ & 67.4 & 0.05 \\
\hline
\end{tabular}

${ }^{\mathbf{a}_{\text {significantly associated factors }}}$

doesn't express their dissatisfaction openly rather internalizing the feeling of misery [95].

The first limitation of this study might be difficulty of establishing temporal relationship between the outcome and independent variables since all the included articles were cross sectional studies. Second, the presence of heterogeneity might be the indicative for the existence of underling effect among primary studies. Third, searching is limited to Ethiopia as result the evidence might not be generalized to other countries in the world.

\section{Conclusion}

In this review and meta-analysis, more than half of health professionals were dissatisfied with their job. Good support from supervisor, working environment, staff relationship, female sex and availability of opportunities for professional growth and development were associated with health professional's job satisfaction. In order to increase the level of job satisfaction the federal ministry of health and stakeholders better to develop a strategy and strength staff relationship, support from supervisors, professional growth opportunities and make the working environment more attractive.

\section{Abbreviations}

Cl: Confidence interval; OR: Odd ratio; SNNP: South nations and nationalities people; SDG: Sustainable development goals; USA: United States of America; WHO: World health organization

\section{Supplementary Information}

The online version contains supplementary material available at https://doi. org/10.1186/s13690-021-00664-7.

Additional file 1.

\section{Acknowledgements}

None.

\section{Authors' contributions}

BG and JN conceived the idea, participated in data extraction, analysis, and draft writing. AM and MM participated in analysis, manuscript preparation and revision. All authors read and approved the final version of the manuscript to be considered for publication.

Funding

Not applicable.

Availability of data and materials

The data included in this study is available and can be accessed by contacting the corresponding author through this email address; bekahegngi@gmail.com or Bekahegng@du.edu.et.

\section{Declarations}

Ethics approval and consent to participate Not applicable.

Consent for publication

Not applicable.

\section{Competing interests}

All authors declare that they have no competing interests.

\section{Author details}

${ }^{1}$ Department of Nursing, College of Medicine and Health Science, Dilla University, Dilla, Ethiopia. ${ }^{2}$ Department of Psychiatry, College of Medicine and Health Science, Dilla University, Dilla, Ethiopia. ${ }^{3}$ Department of reproductive health, School of Public Health, College of Medicine and Health Science, Dilla University, Dilla, Ethiopia.

Received: 17 December 2020 Accepted: 26 July 2021

Published online: 05 August 2021

References

1. Armstrong M. A handbook of human resource management practice, 10th edition. London Philadelphia: Kogan page publishers; 2006.

2. Aziri B. Job satisfaction: a literature review. Manage Res Pract. 2011;3(4):7786.

3. Liu JA, Wang Q, Lu ZX. Job satisfaction and its modeling among township health center employees: a quantitative study in poor rural China. BMC Health Serv Res. 2010;10(1):115. https://doi.org/10.1186/1472-6963-10-115.

4. Organization WH: Health workforce requirements for universal health coverage and the Sustainable Development Goals. (Human Resources for Health Observer, 17). 2016.

5. Luoma M. Increasing the motivation of health care workers. Capacity Project Technical Brief. 2006;7:2-3.

6. Faragher $\mathrm{EB}$, Cass $\mathrm{M}$, Cooper $\mathrm{CL}$. The relationship between job satisfaction and health: a meta-analysis. In: From Stress to Wellbeing Volume 1. London: Springer; 2013. p. 254-71.

7. Ioannou P, Katsikavali V, Galanis P, Velonakis E, Papadatou D, Sourtzi P. Impact of job satisfaction on greek nurses' health-related quality of life. Saf Health Work. 2015;6(4):324-8. https://doi.org/10.1016/j.shaw.2015.07.010. 
8. Bakotić D. Relationship between job satisfaction and organisational performance. Econ Res. 2016;29(1):118-30. https://doi.org/10.1080/1331 677X.2016.1163946.

9. Platis C, Reklitis P, Zimeras S. Relation between job satisfaction and job performance in healthcare services. Procedia Soc Behav Sci. 2015;175(1): 480-7. https://doi.org/10.1016/j.sbspro.2015.01.1226.

10. Hadizadeh Talasaz Z, Nourani Saadoldin S, Taghi Shakeri M. The relationship between job satisfaction and job performance among midwives working in healthcare centers of Mashhad, Iran. J Midwifery Reprod Health. 2014;2(3): 157-64.

11. Santhanam $G$, Jayaraman $R$, Badrinath $V$. Influence of perceived job satisfaction and its impacts on employee retention in Gulf Cooperation Countries. In: 2012-International Conference on Management Issues in Emerging Economies (ICMIEE), vol. 2012. New York: IEEE; 2012. p. 69-73.

12. Aron S: Relationship between nurses' job satisfaction and quality of healthcare they deliver. 2015

13. Farman A, Kousar R, Hussain M, Waqas A, Gillani SA. Impact of job satisfaction on quality of care among nurses on the public hospital of Lahore, Pakistan. Saudi J Med Pharm Sci. 2017;3(6):511-9.

14. Janicijevic I, Seke K, Djokovic A, Filipovic T. Healthcare workers satisfaction and patient satisfaction-where is the linkage? Hippokratia. 2013;17(2):15762.

15. Szecsenyi J, Goetz K, Campbell S, Broge B, Reuschenbach B, Wensing M. Is the job satisfaction of primary care team members associated with patien satisfaction? BMJ Qual Saf. 2011;20(6):508-14. https://doi.org/10.1136/ bmjqs.2009.038166.

16. Yami A, Hamza L, Hassen A, Jira C, Sudhakar M. Job satisfaction and its determinants among health workers in Jimma university specialized hospital, Southwest Ethiopia. Ethiop J Health Sci. 2011;21:19-27.

17. Marinucci F, Majigo M, Wattleworth M, Paterniti AD, Hossain MB, Redfield R. Factors affecting job satisfaction and retention of medical laboratory professionals in seven countries of sub-Saharan Africa. Hum Resour Health. 2013;11(1):38. https://doi.org/10.1186/1478-4491-11-38.

18. Al Otabi M, Shah M, Chowdhury Rl, Al-Enezi N. Determinants of job satisfaction among nurses in Kuwait. Aust J Adv Nurs. 2004;21(4):10.

19. Bergstrom BA, Lunz ME: Measuring job satisfaction: reliability of subscale analysis. 1998

20. Ayanore MA, Amuna N, Aviisah M, Awolu A, Kipo-Sunyehzi DD, Mogre V, et al. Towards resilient health systems in Sub-Saharan Africa: a systematic review of the english language literature on health workforce, surveillance, and health governance issues for health systems strengthening. Ann Glob Health. 2019;85(1):113. https://doi.org/10.5334/aogh.2514.

21. World Health Organization: Global health workforce shortage to reach 12.9 million in coming decades; 2013. Available on: http://www.who int/ mediacentre/news/releases/2013/health-workforce-shortage/en 2014.

22. Gilles I, Burnand B, Peytremann-Bridevaux I. Factors associated with healthcare professionals' intent to stay in hospital: a comparison across five occupational categories. Int J Qual Health Care. 2014;26(2):158-66. https:// doi.org/10.1093/intqhc/mzu006.

23. Nabirye RC, Brown KC, Pryor ER, Maples EH. Occupational stress, job satisfaction and job performance among hospital nurses in Kampala, Uganda. J Nurs Manag. 2011;19(6):760-8. https://doi.org/10.1111/j.1365-2 834.2011.01240.x

24. Blaauw D, Ditlopo P, Maseko F, Chirwa M, Mwisongo A, Bidwell P, et al. Comparing the job satisfaction and intention to leave of different categories of health workers in Tanzania, Malawi, and South Africa. Glob Health Action. 2013;6(1):19287. https://doi.org/10.3402/gha.v6i0.19287.

25. Pillay R. Work satisfaction of professional nurses in South Africa: a comparative analysis of the public and private sectors. Hum Resour Health. 2009;7(1):15. https://doi.org/10.1186/1478-4491-7-15.

26. Chaulagain N, Khadka DK. Factors influencing job satisfaction among healthcare professionals at Tilganga eye Centre, Kathmandu, Nepal. Age. 2012;35(56):74.67.

27. Khamlub S, Harun-Or-Rashid M, Sarker MAB, Hirosawa T, Outavong P, Sakamoto J. Job satisfaction of health-care workers at health centers in Vientiane capital and Bolikhamsai Province, Lao PDR. Nagoya J Med Sci. 2013;75(3-4):233-41

28. Schwendimann R, Dhaini S, Ausserhofer D, Engberg S, Zúñiga F. Factors associated with high job satisfaction among care workers in Swiss nursing homes-a cross sectional survey study. BMC Nurs. 2016;15(1):37. https://doi. org/10.1186/s12912-016-0160-8
29. Lefton C. Strengthening the workforce through meaningful recognition. Nurs Econ. 2012;30(6):331-8, 355

30. Faramarzpour M, Borhani F, Bagheri P. Job satisfaction of nurses from clinical practice in Jiroft University hospitals. Iran J Nurs. 2015;28(97):77-86.

31. EE E: Job satisfaction among nurses working in Mansoura university hospital: effect of socio-demographic and work characteristics. Egypt J Occup Med 2018, 42(2):227-240, DOl: https://doi.org/10.21608/ejom.2018.6807.

32. Kohli S, Bagga R. Job satisfaction amongst contractual and regular nursing staff in two government hospitals of Delhi: a comparison. Health Popul Perspect Issues. 2013;36:98-107.

33. Temesgen K, Aycheh MW, Leshargie CT. Job satisfaction and associated factors among health professionals working at Western Amhara region, Ethiopia. Health Qual Life Outcomes. 2018;16(1):65. https://doi.org/10.1186/ s12955-018-0898-7.

34. MENGESHA M, TIGABU BM. Job satisfaction of pharmacists in Ethiopia: the case of Harar town. Age. 2014;29(32):74.74.

35. Moher D, Liberati A, Tetzlaff J, Altman DG. Preferred reporting items for systematic reviews and meta-analyses: the PRISMA statement. Ann Intern Med. 2009;151(4):264-9, w264. https://doi.org/10.7326/0003-4819-151-4-2 00908180-00135.

36. Peterson J, Welch V, Losos M, Tugwell P. The Newcastle-Ottawa scale (NOS) for assessing the quality of nonrandomised studies in meta-analyses. Ottawa: Ottawa Hospital Research Institute; 2011.

37. Tang W, Hu J, Zhang H, Wu P, He H. Kappa coefficient: a popular measure of rater agreement. Shanghai Arch Psychiatry. 2015;27(1):62-7. https://doi. org/10.11919/j.issn.1002-0829.215010.

38. Sterne JA, Egger M. Funnel plots for detecting bias in meta-analysis: guidelines on choice of axis. J Clin Epidemiol. 2001;54(10):1046-55. https:// doi.org/10.1016/S0895-4356(01)00377-8.

39. Egger M, Smith GD, Schneider M, Minder C. Bias in meta-analysis detected by a simple, graphical test. Bmj. 1997;315(7109):629-34. https://doi.org/1 0.1136/bmj.315.7109.629.

40. Higgins JP, Thompson SG, Deeks JJ, Altman DG. Measuring inconsistency in meta-analyses. Bmj. 2003;327(7414):557-60. https://doi.org/10.1136/bmj.327. 7414.557.

41. Borenstein M, Hedges LV, Higgins JP, Rothstein HR. Fixed-effect versus random-effects models. Introduction Metaanal. 2009;77:85.

42. Patsopoulos NA, Evangelou E, loannidis JP. Sensitivity of between-study heterogeneity in meta-analysis: proposed metrics and empirical evaluation. Int J Epidemiol. 2008;37(5):1148-57. https://doi.org/10.1093/ije/dyn065.

43. Bown MJ, Sutton AJ. Quality control in systematic reviews and metaanalyses. Eur J Vasc Endovasc Surg. 2010;40(5):669-77. https://doi.org/10.101 6/j.ejvs.2010.07.011.

44. Marušić MF, Fidahić M, Cepeha CM, Farcaș LG, Tseke A, Puljak L. Methodological tools and sensitivity analysis for assessing quality or risk of bias used in systematic reviews published in the high-impact anesthesiology journals. BMC Med Res Methodol. 2020;20(1):121. https://doi. org/10.1186/s12874-020-00966-4.

45. Hotchkiss DR, Banteyerga $H$, Tharaney M. Job satisfaction and motivation among public sector health workers: evidence from Ethiopia. Hum Resour Health. 2015;13(1):83. https://doi.org/10.1186/s12960-015-0083-6.

46. Negussie N, Demissie A. Relationship between leadership styles of Nurese managers and nurses' job satisfaction in Jimma University specialized hospital. Ethiop J Health Sci. 2013;23(1):50-8.

47. Gebregziabher D, Berhanie E, Berihu H, Belstie A, Teklay G. The relationship between job satisfaction and turnover intention among nurses in Axum comprehensive and specialized hospital Tigray, Ethiopia. BMC Nurs. 2020; 19(1):1-8.

48. SALEH M. Factors affecting job satisfaction among medical representatives working in multinational pharmaceutical companies in Addis Ababa. Addis Ababa: St. Mary's University; 2018.

49. Gudeta NS, Ambo E. Comparative study on job satisfaction among health workers in public and private sector hospitals at South-West Shoa Zone, Oromia Regional State, Ethiopia. Glob J Hum-Soc Sci Arts Hum. 2017;17(2): 32-33.

50. Gudeta N. Job satisfaction across some selected demographic variables among hospital health Workers in South-West Shoa Zone, Oromia regional state, Ethiopia. Inter J Clinic Oncol Cancer Res. 2017;2(1):22-8.

51. Mariam DH, Tassew B, Nega A, Assefa D, Siraw D, Tebekaw $Y$, et al. Expectations and satisfaction of urban health extension workers regarding their service delivery environment. Ethiop J Health Dev. 2020;34(2):70-4. 
52. Abadiga M, Nemera G, Hailu E, Mosisa G. Relationship between nurses' perception of ethical climates and job satisfaction in Jimma University specialized hospital, Oromia region, south West Ethiopia. BMC Nurs. 2019; 18(1):39. https://doi.org/10.1186/s12912-019-0365-8.

53. Admasu B, Temamen T, Dagmawit B, Abdela A. Job satisfaction and associated factors among nurses working in the operation theater at government hospitals of eastern Ethiopia, 2017. Palliat Med Care. 2018;5(2): $1-7$.

54. Ahmed SM, Tolera M, Angamo MT. Assessment of job satisfaction among pharmacy professionals in south-West Ethiopia. Int J Pharm Sci Res. 2013; 4(6):2351.

55. Asegid A, Belachew T, Yimam E. Factors influencing job satisfaction and anticipated turnover among nurses in Sidama zone public health facilities, South Ethiopia. Nurs Res Pract. 2014;2014:1-18

56. Ayalew $\mathrm{E}$, Workineh $\mathrm{Y}$. Job satisfaction and associated factors among nurses in Bahir Dar city administrative, north West Ethiopia, 2017. BMC Res Notes. 2019;12(1):1-5

57. Ayalew F, Kibwana S, Shawula S, Misganaw E, Abosse Z, Van Roosmalen J, et al. Understanding job satisfaction and motivation among nurses in public health facilities of Ethiopia: a cross-sectional study. BMC Nurs. 2019;18(1):46. https://doi.org/10.1186/s12912-019-0373-8

58. Ayele M, Abraham G. Job satisfaction and associated factors among rural health extension Workers in East Shoa Zone, Oromia regional state, Ethiopia. Prim Health Care Open Access. 2020;10(2):1-7.

59. Ayele $Y$, Hawulte B, Feto T, Basker GV, Bacha YD. Job satisfaction among pharmacy professionals working in public hospitals and its associated factors, eastern Ethiopia. J Pharm Policy Pract. 2020;13:1-9.

60. Azagew AW, Mekonnen C: Nurse practitioners' job satisfaction and associated factors among nurses working at the University of Gondar Specialized Hospital: a cross-sectional survey study. 2020.

61. Bekru ET, Cherie A, Anjulo AA. Job satisfaction and determinant factors among midwives working at health facilities in Addis Ababa city, Ethipia. PloS one. 2017;12(2):e0172397. https://doi.org/10.1371/journal.pone.0172397.

62. Belay YB. Job satisfaction among community pharmacy professionals in Mekelle city, Northern Ethiopia. Adv Med Educ Prac. 2016;7:527-31. https:// doi.org/10.2147/AMEP.S116147.

63. Deriba BK, Sinke SO, Ereso BM, Badacho AS. Health professionals' job satisfaction and associated factors at public health centers in West Ethiopia. Hum Resour Health. 2017;15(1):36. https://doi.org/10.1186/s12960-017-02 06-3.

64. Desalegn N, Akalu L, Haile M. Ethiopian anesthetists job satisfaction level and factors affecting their level of job satisfaction. J Anesthesiol. 2015:3(5): 17-24.

65. Gedif G, Sisay $Y$, Alebel A, Belay YA. Level of job satisfaction and associated factors among health care professionals working at University of Gondar Referral Hospital, Northwest Ethiopia: a cross-sectional study. BMC Res Notes. 2018;11(1):824. https://doi.org/10.1186/s13104-018-3918-0.

66. Geleto A, Baraki N, Atomsa GE, Dessie Y. Job satisfaction and associated factors among health care providers at public health institutions in Harari region, eastern Ethiopia: a cross-sectional study. BMC Res Notes. 2015;8(1): 394. https://doi.org/10.1186/s13104-015-1368-5.

67. Haile D, Gualu T, Zeleke H, Dessalegn B. Job satisfaction and associated factors among nurses in east Gojjam zone public hospitals Northwest Ethiopia, 2016. J Nurs Care. 2017;6(398):2167-1168.1000398.

68. Kibwana S, Yigzaw M, Molla Y, van Roosmalen J, Stekelenburg J. Job satisfaction among anesthetists in Ethiopia - a national cross-sectional study. Int J Health Plann Manag. 2018;33(4):e960-70. https://doi.org/10.1002/ hpm.2573.

69. Mengistu MM, Bali AG. Factors associated to job satisfaction among healthcare workers at public hospitals of west Shoa zone, Oromia regional state, Ethiopia: a cross sectional study. Sci J Public Health. 2015;3(2):161-7. https://doi.org/10.11648/j.sjph.20150302.12.

70. Merga H, Fufa T. Impacts of working environment and benefits packages on the health professionals' job satisfaction in selected public health facilities in eastern Ethiopia: using principal component analysis. BMC Health Serv Res. 2019;19(1):494. https://doi.org/10.1186/s12913-019-4317-5.

71. Meselu BT, Wondie AT, Shedie TA, Tibebu MA: Job Satisfaction and Associated Factors Among Midwives Working in Health Centers of Central Zone, Ethiopia. 2020.

72. Mohammed E, Daybaso HA, Habtewold EM: Job satisfaction, engagement and associated factors among employees working at Adama hospital medical college, Adama, Oromia Regional State, Ethiopia: Institution Based Cross Sectional Study. 2020.

73. Kitaba M, Gobena T, Dessie Y, Fituma S. Job Satisfaction and Its Determinants among Nurses in Harari Region and Dire Dawa Administration, Eastern Ethiopia. Journal of Culture, Society and Development. 2017;31:31-6.

74. Tadese T, Mohamed A, Mengistie A. Assessment of factors influencing job satisfaction among health care providers, federal police referral hospital, Addis Ababa, Ethiopia. Ethiop J Health Dev. 2015;29(2):119-125.

75. Teka AA. Assessment of factors affecting job satisfaction and its association with anticipated turnover: the case of health professionals in Arsi zone, Oromia region, Ethiopia 2016. J Strat Hum Resour Manage. 2018;7(1):17.

76. Workineh I, Dida N, Sileshi T: Job satisfaction and its associated factors among governmental health Workers in West Shoa Zone, Oromia, Ethiopia. 2020.

77. Yilkal Fentie D, Enyew Ashagrie H, Getinet Kasahun H. Job satisfaction and associated factors among anesthetists working in Amhara National Regional State, Northwest Ethiopia, may 2017: a multicenter cross-sectional study. Anesthesiol Res Pract. 2018;2018:1-6. https://doi.org/10.1155/2018/6489674.

78. Yimam W, Kumara P, Tsegaye D, Getachew Y. Motivation, hygiene factors and job satisfaction among health workers working at six government hospitals, Addis Ababa, Ethiopia. Int J Intg Med Sci. 2017;4(7):543-7.

79. Dilig-Ruiz A, MacDonald I, Varin MD, Vandyk A, Graham ID, Squires JE. Job satisfaction among critical care nurses: a systematic review. Int J Nurs Stud. 2018;88:123-34. https://doi.org/10.1016/j.jijurstu.2018.08.014.

80. Carrillo-García C, Solano-Ruíz Mdel C, Martínez-Roche ME, Gómez-García Cl. Job satisfaction among health care workers: the role of gender and age. Rev Lat Am Enfermagem. 2013;21(6):1314-20. https://doi.org/10.1590/01 04-1169.3224.2369.

81. Bhattacherjee S, Ray K, Kumar Roy J, Mukherjee A, Roy H, Datta S. Job satisfaction among doctors of a government medical college and Hospital of Eastern India. Nepal J Epidemiol. 2016;6(3):596-602.

82. Aletras VH, Kostarelis A, Tsitouridou M, Niakas D, Nicolaou A. Development and preliminary validation of a questionnaire to measure satisfaction with home care in Greece: an exploratory factor analysis of polychoric correlations. BMC Health Serv Res. 2010;10(1):189. https://doi.org/10.1186/14 72-6963-10-189.

83. Holland E. Key Factors to Finding Job Satisfaction. In.: The Chopra Center Khalf, S.(2016), The level of Job Satisfaction among EFL ... ; 2016.

84. Kumar R, Ahmed J, Shaikh BT, Hafeez R, Hafeez A. Job satisfaction among public health professionals working in public sector: a cross sectional study from Pakistan. Hum Resour Health. 2013;11(1):2-2. https://doi.org/10.1186/14 78-4491-11-2.

85. Ayamolowo SJ. Job satisfaction and work environment of primary health care nurses in Ekiti state, Nigeria: an exploratory study. Int J Caring Sci. 2013; 6(3):531.

86. McAuliffe E, Daly M, Kamwendo F, Masanja H, Sidat M, de Pinho $H$. The critical role of supervision in retaining staff in obstetric services: a three country study. PLoS One. 2013;8(3):e58415. https://doi.org/10.1371/journal. pone.0058415.

87. van der Doef M, Mbazzi FB, Verhoeven C. Job conditions, job satisfaction, somatic complaints and burnout among east African nurses. J Clin Nurs. 2012;21(11-12):1763-75. https://doi.org/10.1111/j.1365-2702.2011.03995.x.

88. Kula S, Guler A. Influence of supervisor support on job satisfaction levels: an evaluation of Turkish National Police (TNP) officers in the istanbul police department. Int J Crim Justice Sci. 2014;9(2):209-24.

89. Aziz I, Kumar R, Rathore A, Lal M. Working environment and job satisfaction among health professional working at a tertiary care hospital of Pakistan. J Ayub Med Coll Abbottabad. 2015;27(1):201-4.

90. Sharma A, Khanna M. Job satisfaction among Bank employees-a study on district Hamirpur (HP). Int J Sci Environ. 2014;3(4):1582-91.

91. Rahman M, Akhter R, Chowdhury S, Islam S, Haque R. HRM practices and it impact on employee satisfaction: a case of pharmaceutical companies in Bangladesh. Int J Res Bus Soc Sci. 2013;2(3):62-7.

92. Ramasodi JMB: Factors influencing job satisfaction among healthcare professionals at south Rand Hospital. 2012.

93. Hariyati RTS, Safril S. The relationship between nurses' job satisfaction and continuing professional development. Enferm Clin. 2018;28:144-8. https:// doi.org/10.1016/S1130-8621(18)30055-X.

94. Kalisch BJ, Lee $H$, Rochman M. Nursing staff teamwork and job satisfaction. J Nurs Manag. 2010;18(8):938-47. https://doi.org/10.1111/j.1365-2834.2010.011 53.x. 
95. Hagan J, Kay F. Even lawyers get the blues: gender, depression, and job satisfaction in legal practice. Law Soc Rev. 2007;41(1):51-78. https://doi.org/1 0.1111/j.1540-5893.2007.00291.x.

\section{Publisher's Note}

Springer Nature remains neutral with regard to jurisdictional claims in published maps and institutional affiliations.

- fast, convenient online submission

- thorough peer review by experienced researchers in your field

- rapid publication on acceptance

- support for research data, including large and complex data types

- gold Open Access which fosters wider collaboration and increased citations

- maximum visibility for your research: over $100 \mathrm{M}$ website views per year

At $\mathrm{BMC}$, research is always in progress. 